\title{
THE LARGEST RENEWABLE, EASILY EXPLOITABLE, AND ECONOMICALLY SUSTAINABLE
}

\section{ENERGY RESOURCE}

I Giancarlo Abbate' and Eugenio Saraceno ${ }^{2}$ - DOI: https://doi.org/10.1051/epn/2018101

I 1 Università di Napoli "Federico II" - Naples, Italy - abbate@unina.it - ${ }^{2}$ KiteGen Venture S.p.a. - Caselle (Turin), Italy

Sun, the ultimate energy resource of our planet, transfers energy to the Earth at an average power of 23,000 TW. Earth surface can be regarded as a huge panel transforming solar energy into a more convenient mechanical form, the wind. Since millennia wind is recognized as an exploitable form of energy and it is common knowledge that the higher you go, the stronger the winds flow. To go high is difficult; however Bill Gates cites high wind among possible energy miracles in the near future. Public awareness of this possible miracle is still missing, but today's technology is ready for it. 
7 ropospheric Wind Energy or High Altitude Wind Energy (HAWE), also known as highwind energy, is a vast and well-known kinetic energy resource. The atmospheric stationary regime is powered by a percentage of the total mean solar radiation $\left(230 \mathrm{~W} / \mathrm{m}^{2}\right.$ after reflection to space) around $2 \%$. Gustavson in 1979 [1] estimated the power needed to maintain the stationary regime of the atmosphere as huge as 3,600 TW.

Of the 3,600 TW figure, the near-surface wind resources available to wind turbines are in the range 25-70 TW, see figure 1.

Near-surface wind and solar technologies also deal with low capacity factors. The most efficient solar technology, solar photovoltaics, suffers from a tradeoff between capital cost and capacity factor. Availability only during daylight hours and weather variability are also drawbacks needing expensive power backup and storage to assure a reliable supply. Wind turbines deal with the lack of good sites that must have strong and constant winds to harness. Offshore installations deal with the strong increase of capital cost. This is reflected by the persistent need for subsidy by the solar and wind power investments to be profitable. In figure 2.a, a real example [3] is shown, where the power curve reaches its nominal value only in the queue of the wind speed distribution, resulting in a quite low capacity factor ${ }^{1}$.

High-wind resources around 1-2.5 km above ground level, on the other hand, enjoy a much higher mean speed, as shown in figure 2.b [4], being more constant and intense. Consequently, High Altitude Wind Energy System (HAWES) capacity factor can reach values more than twice the one exhibited by a best-class wind turbine [see Figure 4]. In a big and fundamental work of 2008, Archer and Caldera [5] showed that at high altitude, say beyond 500$800 \mathrm{~m}$ above ground level, strong winds are present almost everywhere around the globe and almost always. Thus, for a HAWES not only the issue of capacity factor but also "the lack of good sites" has been eliminated or at least drastically reduced (see, for instance, the work of Yip, Gunturu, and Stenchikov for the Middle East resource [6]).

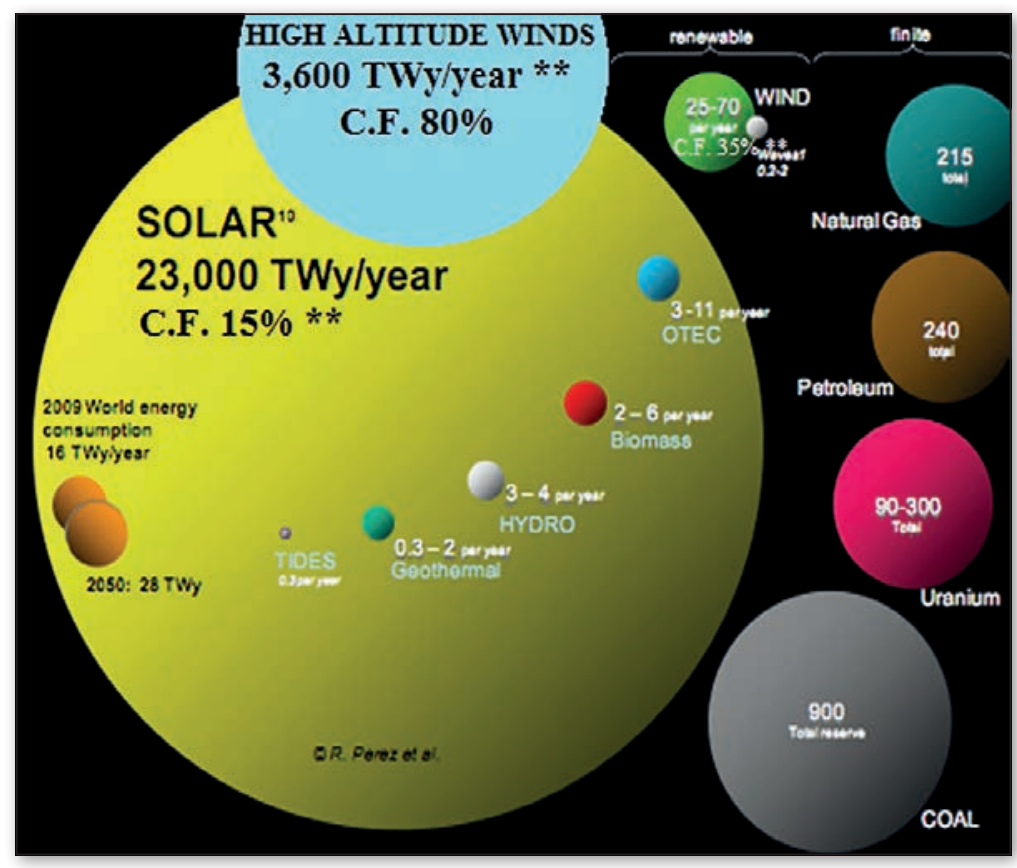

Now, the opportunity is to develop HAWES by means of an economically sustainable technology, in order to harvest the most productive available resources. In this way, it will be possible to reduce the production cost and increase the amount and the quality of the renewable energy supply (i.e. no or minimal intermittency).

\section{HAWES technology development}

In the last decade, HAWE technologies promised to overcome the windmills drawbacks by three main drivers:

- Reach for higher altitudes, where winds are stronger and constant

- Dematerialization: lighter devices to reduce capital and maintenance costs

- Harvest a wider area than the windmill blades can do.

Although the high wind resource exploitation had been investigated since the $19^{\text {th }}$ century by G.Pocock [7] and later by the theoretical work of Loyd [8], no relevant technological development was performed up to the early 2000s. $\triangle$ FIG. 1: Power and energy resources [2].

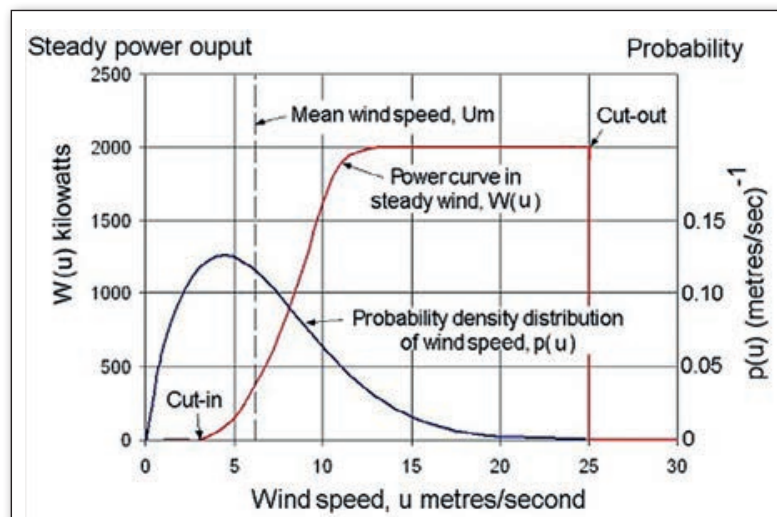

Steady wind power curve and wind speed probability density

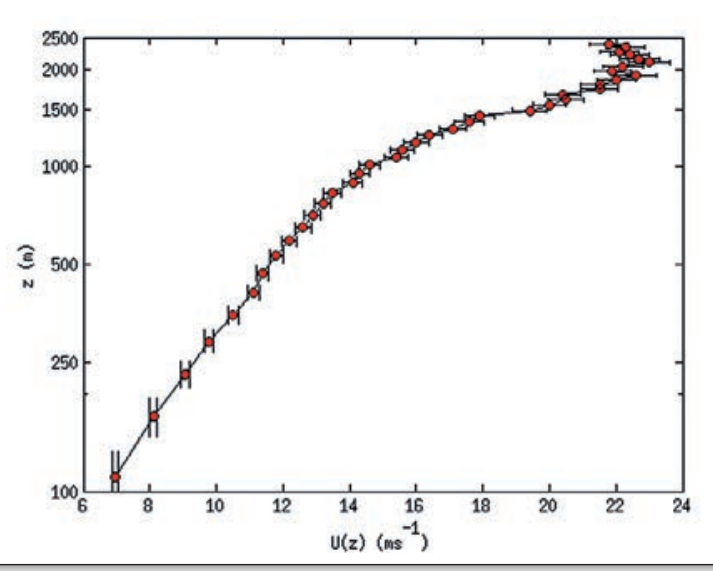

4 FIG. 2: (a) Wind speed probability (blue line) and power curve (red line) for a Vestas $90 \mathrm{~m} 2 \mathrm{MW}$ wind turbine [3]; (b) Measured mean wind speed vs. altitude over Greater London using a Doppler Lidar.[4] 


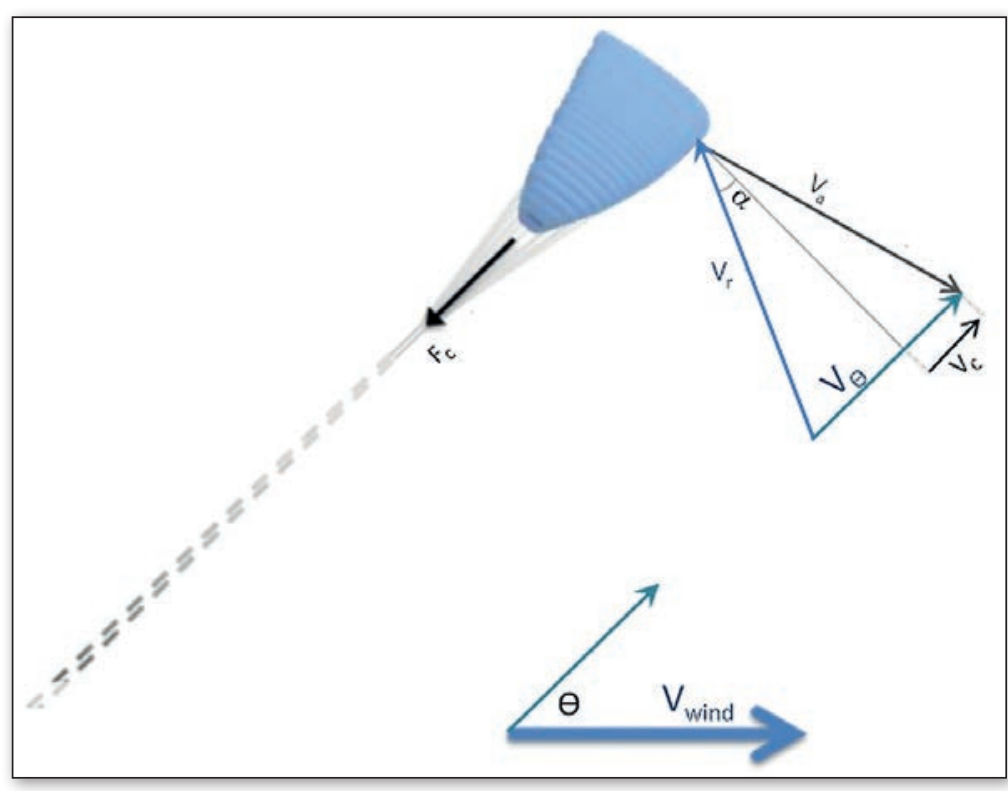

$\triangle$ FIG. 3: Schematic of force and velocities for a tethered kite where $V_{a}$ is the wing absolute speed and $V_{r}$ is the wing relative speed.

Then, the availability of new light materials featuring high stress resistance, like ultra-high molecular weight polyethylene fibers (UHMWPE), or composite carbon/Kevlar materials, together with advances in computer science and control techniques, changed the scenario. Several private companies, universities, and public research centres were able to realize and control some small-scale High Altitude Wind Energy Systems. The first HAWES prototype that successfully produced some energy, using a $5 \mathrm{~m}^{2}$ sport kite controlled by a truck-mounted engine, was a device called MobilGen, by the Italian company KiteGen Research S.r.l.. In the following years, many players succeeded in realizing $\mathrm{kW}$ class HAWES prototypes using kites or drones. Among others, we cite: KiteGen 2006 [9], TU Delft 2007 [10], Makani Power 2009 [11], Swiss kite power 2009 [12], Windlift 2010 [13], TU Delft 2012 [14], NASA 2012 [15], KiteGen 2012 [16], TWINGTECH 2013 [17].

A quite comprehensive review of HAWES technologies can be found in a recent paper by Cherubini et al [18]. Many different technologies were proposed for the exploitation of high altitude wind, divided in two main classes, with electric generation at a ground station (groundgen), and with onboard generation (flygen). In the following, we shall focus on groundgen technology, because it appears the most viable, especially from an economic point of view. The working principle of a groundgen machine is very simple. A kite, tethered by one rope (or two) to a ground station, flies crosswind and exerts a lift force on the rope(s). The rope tension is transmitted to alternators, through a pulley and a drum, around which the rope is wrapped. Unwrapping of the rope let the alternators generate electric energy.

Taken for granted the proof of concept of the feasibility of HAWES energy production, as all those players were able to confirm, there have been since then some research debates that need to be solved. Scalability of the concept, from the $\mathrm{kW}$ class of the prototypes to the MW class, has to be assessed. At the same time, also economical sustainability of HAWES technologies should be proved, and the two issues are related to each other. In fact, it is easily shown that a HAWES $\mathrm{kW}$ class power plant is not able to pay for the hourly wage of a supervisor or maintenance operator.

We shall base the following discussions mainly taking into account the technological developments made by KiteGen Research[19], in particular because it appears the only, or at least the most advanced, player oriented towards large-scale HAWES.

\section{Issue1: inconvenience of Loyd model}

According to the paper of M.L.Loyd [8], the following equations describe the behaviour of a tethered kite wing: $V_{c} \approx V_{\theta}-\sqrt{\frac{2 F_{C}}{\rho K_{P F}}} ; F_{C} \approx \frac{1}{2} \rho\left(V_{\theta}-V_{C}\right)^{2} K_{P F} ; P \approx \frac{1}{2} \rho V_{C}\left(V_{\theta}-V_{C}\right)^{2} K_{P F} ;$ where $V_{c}$ is the reel-out speed of the ropes, $V_{\theta}$ is the component of the speed of the wind parallel to the ropes, $F_{c}$ is the load on the ropes and $P$ is the output power, $\rho$ is the air density. In Loyd's equations, $K_{p F}$, the Kite Power Factor, is defined as $K_{p F}=S E^{2} C_{L}=S \frac{C_{L}^{3}}{C_{D}^{2}}$, where $S$ is the kite surface area, $C_{L}$ and $C_{D}$ the lift and drag coefficient, and $E$ is the lift to drag ratio, also known as aerodynamic efficiency. Figure 3 geometrically shows these relationships.

Loyd calculated that the optimum of the power can be obtained when $V_{c} \approx 1 / 3 V_{\theta}$. It can be easily shown (see the red dashed curve in figure 4) that, following this optimization, if the Kite Power Factor is higher than the one of a sport kite, with aerodynamic efficiency ranging from 5 to 10 , the force on the rope raises sharply and becomes unmanageable, as the wind speed exceeds $12-15 \mathrm{~m} / \mathrm{s}$. This event is very frequent at altitudes over $500 \mathrm{~m}$. Consequently, this is a main critic to HAWES, as it negatively affects the capacity factor.

The control theory, however, has a different point of view and it is used to safeguard the system instead of seeking the optimum performance. In the following the given equations are used to calculate the power curve, shown in figure 4 , as function of the natural wind speed. There are three productive phases, corresponding to three areas of the curve:

1. B: wind speed is above the minimum (i.e. beyond cut-off area A) but not enough to exert the maximum force; the force is exploited to increase the altitude and find more wind. A little amount of power can also be produced as the rope is reeling out. During this phase, forces are still low and some Loyd optimization may be performed by the control system trying to maintain $V_{c} \approx 1 / 3 V_{\theta}$. 
2. C: wind speed is enough to exert the maximum force. Electronic control, hardware and software, is performed in order to maintain the force constant, while the ropes reel out at a proper, variable speed. Since force is constant, a power proportional to the reel-out speed is produced. This strategy means that the Loyd optimization curve has been abandoned to safeguard the system, while wind speed increases.

3. D: wind speed reaches and passes the maximum possible for phase 2, because reel-out speed cannot be increased any more. To keep constant both maximum force and maximum reel-out speed, the electronic control displaces the ropes by an angle $\varphi$, driving the kite out from the centre of the power window. In this phase, the power output is damped to $P_{M a x}$. Notice that $P_{M a x}$ is greater than the nominal power, to compensate the energy consumed during the passive phase of the production cycle (i.e. when the rope is completely extended and must be recovered).

Let us provide some values of physical parameters, reasonable for a large-scale HAWES, to give an estimated power curve. (Notice that most of them are taken from the design, or actual realization, of a KiteGen prototype).

- Max generator power $P_{\text {Max }}=4 \mathrm{MW}$

- Nominal generator power $3 \mathrm{MW}$

- Wing surface $S=150 \mathrm{~m}^{2}$

- Wing Lift factor $C_{L}=1.2$

- Wing Drag factor $C_{D}=0.04$

- Wing Aerodynamic efficiency E=30

- Wing weight $287 \mathrm{~kg}$

- Max load 20 tons for each rope for a total $F_{c \text {, }}$ ${ }_{\text {Max }}=400 \mathrm{kN}$

- Rope diameter 22 mm (Dyneema SK75)

- Rope length 3536 m

- Rope weight $1948 \mathrm{~kg}$

- Minimum operative altitude $2100 \mathrm{~m}$

- Maximum altitude 2500

- Working angle $\theta=45^{\circ}$ (rope vs ground)

- Maximum reel-out speed $V_{c, \text { Max }}=10 \mathrm{~m} / \mathrm{s}$

- Maximum reel-in speed $20 \mathrm{~m} / \mathrm{s}$

- Cycle time $1 \mathrm{~min}-10 \mathrm{~min}$

- These parameters are used for the calculation of force and power.

Figure 4, courtesy of KiteGen Research, shows the power curve, the three operative areas and the related equations given the speed and force constraints for a KiteGen Stem unit. At the bottom of Figure 4 is also shown the probability density distribution for wind velocity at the altitude of $2300 \mathrm{~m}$ a.g.l., in the same horizontal scale of the power curve.

It can be seen that the 3-phase control strategy allows exploiting winds that are well stronger than the Loyd optimization strategy would have made possible. In other words, the criticism to HAWES, founded upon Loyd optimization model, is not consistent because, when there is excess of available power, there is no need to reach the highest power with the actual wind; it is more advisable wasting some power to increase the capacity factor and the safety of the system. A comparison of Figure 4 with Figure 2a makes clear immediately how much larger the CF for a HAWES can be than for the standard wind turbine.

\section{Issue2: importance of the aerodynamic efficiency}

As seen, aerodynamic efficiency plays a quadratic role in the forceexerted by theflying device. This means that it is as important as the wind speed. Higher efficiencies allow working with lower wind speed and having kites of smaller surface. High efficiency kites for power production are a totally new concept, because this feature is not useful for sport and leisure kites and would be harmful for people using them. HAWES developers are realizing several different concepts of high efficiency kite or drone (Makani, Twingtech tensarity wing, KG power wing). Generally, rigid or semi-rigid

vFIG. 4: (From top to down) Relevant equations for power generation; power curve for a 3MW HAWES (red); Weibull probability density distribution for wind velocity @ $2300 \mathrm{~m}$ a.g.l. with $V_{M}=12 \mathrm{~m} / \mathrm{s}$ [20]

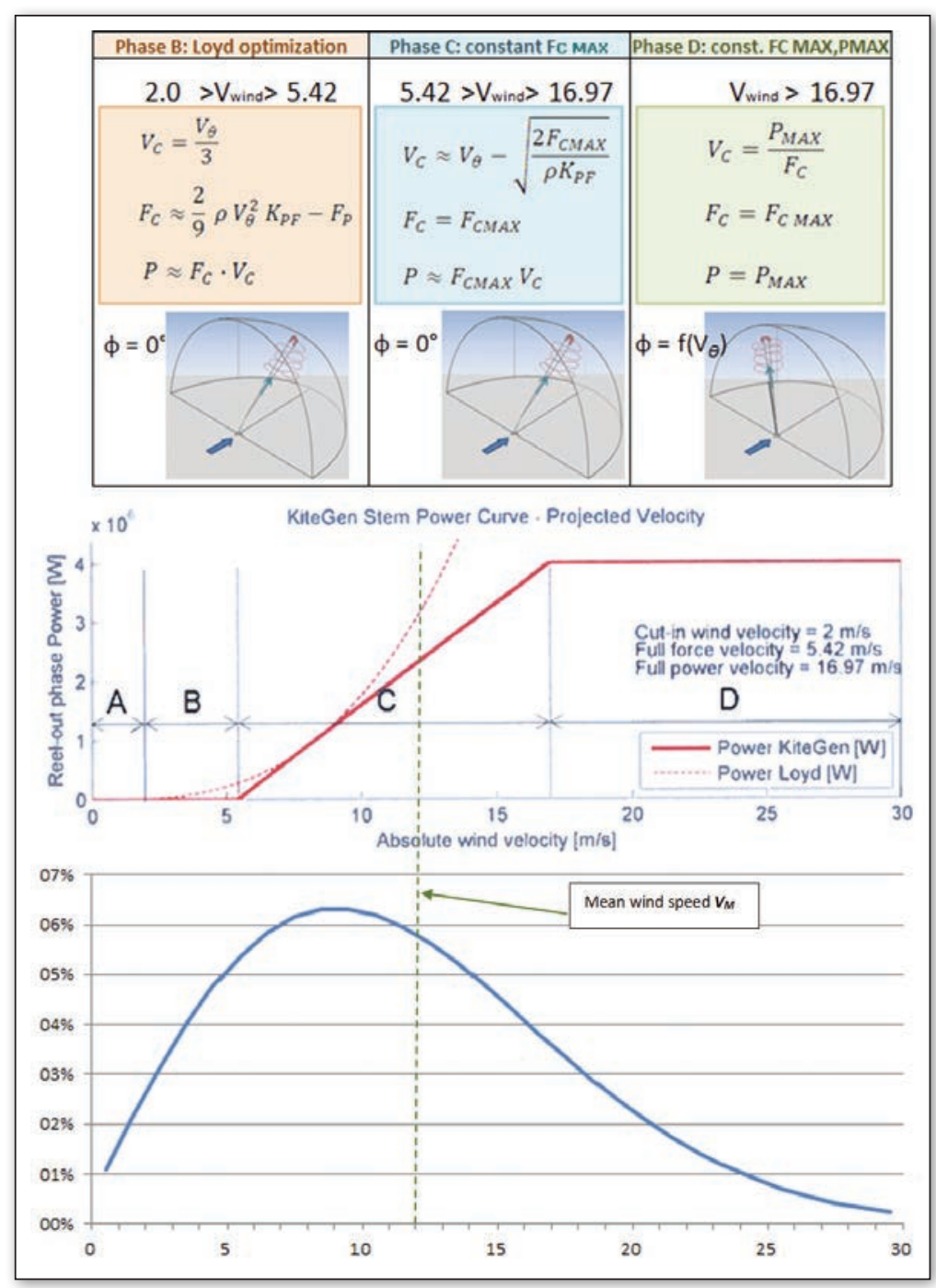


materials have been preferred for this scope, and also to more safely host sensor devices that could be damaged because of the fluttering phenomena associated with flying devices made of flexible materials. Given its relevant role in the power generation of HAWES, the aerodynamic efficiency must be accounted very accurately in analytical modeling and simulation, and in experimental measurements. In the 3-phase power curve simulation shown above, the authors used a value $\mathrm{E}=30$, close to the value obtained in the experimental tests by his company. In a very important paper [21], by Argatov and coworkers, the authors introduced a larger value $E=37$, but then used in their numerical simulation an "effective" glide ratio equal to 10 , by the following argument. The kite is tethered to the ground station by a rope that moves through the air and is subject to a drag force; this drag affects the aerodynamic efficiency decreasing its value to the estimated "effective" glide ratio. We shall come back to the rope drag problem in the next paragraph, however we should emphasize now that, in a careful design, between the rope and the kite there is a mechanical coupling that allows the top of the rope to be always aligned with the tension provided by the kite. Thus, no aerodynamic effect by the rope drag can be envisaged. Instead, the rope drag force can change the flight direction of the kite, possibly forcing the kite out of the centre of the power zone. In the last case, the electronic control drives the kite along a corrected path to reach again the high-power spot.

\section{Issue 3. The rope drag problem, weakness of the Argatov model}

In a number of articles [21-23], Argatov and coworkers made an upgrade and a refinement of the old Loyd's work of 1980, with the aim to estimate the energy output of a HAWES based on the pumping kite technology, the same described in the present paper. These works appeared at the right moment, when several experimental demonstrations of HAWES feasibility were performed in different countries, and there was a real need of a theoretical analysis and estimations based on more realistic and accurate basis. However, the problem is very complex from an analytic point of view, involving continuous variables interacting with each other. Thus, the authors made several approximations, even though they released few of them in the last paper. Unfortunately, some of the maintained assumptions have proved to be unrealistic letting a large uncertainty in the final results, especially the quantitative ones.

We notice that Argatov and coworkers afforded the problem in a correct way, but probably they underestimate the strong quantitative, and in some cases also qualitative, influence of the approximations involved in their analysis. We also underline that one of their most important conclusion, namely that "actually during the kite's cross-wind motion only the upper part of the tether will contribute into the equivalent air resistance of tether" [21], appears correct and in agreement with the experimental findings.

However, their final quantitative conclusion, and the corresponding numerical simulation on a HAWE system considered typical by them, is in striking contrast with their previous sentence, showing that the longer is the rope, the less efficient is the extraction of mechanical energy. This result, if correct, would have been a heavy drawback for HAWES. In fact, the operative altitude should have been reduced and consequently the quality and speed of the available wind resource.

First, in Argatov's model, the rope is treated as a rigid body, even when sag is considered. Propagation phenomena along the rope and transversal deformations are neglected. Secondly, in the pumping kite technology the rope tension is kept constant, but not its length as assumed in the model. The consequence is an unrealistic rigid shape of the moving rope, and an overestimation of its drag that is added to the unnecessary decrease of the glide ratio. Last, the rope tension is assumed uniform along the rope in the calculation of the drag that, in turn, reduces the tension: this is an evident inconsistence of the model. All these assumptions go in the same direction of reducing more and more the system efficiency, when the kite flies higher and higher, so damping the power curve at height less than 1000 meters. Finally, in the worked-out simulation shown to test their model, Argatov and coworkers used parameter values taken from Fagiano (2009) [24], including a kite surface area of $10 \mathrm{~m}^{2}$ that is $13-14$ times less than the actual value of the design and experimental realization of the present technology. Since in the Argatov's model the kite area affects strongly the value of its effective glide ratio, we can conclude that, even in the frame of its assumptions, that simulation and related suggestions are outdated and have no real meaning, at present.

A recent thesis work by F. Roselli [25] is devoted to the same problem of evaluation of the rope drag, but considering the rope flexible and with a variable length, as it is. A numerical computation shows that, for ropes longer than $900 \mathrm{~m}$, there is a significant deviation from the Argatov's model, and the drag tends asymptotically to a lower value. Summarizing here, the rope drag is not an issue because it only affects the cut-in wind speed, slightly raising it. The energy wasted by the ropes is paid by a speed offset of the reeling out due to the envelope of the bending, counter bending and swing behaviour. However it brings other advantages like an expansion 


\begin{tabular}{|c|c|c|c|c|}
\hline COMPANY & SHORT DESCRIPTION & STATE OF ART & DRAWBACKS & PICTURE \\
\hline $\begin{array}{l}\text { Makani } \\
\text { Power USA }\end{array}$ & $\begin{array}{l}\text { FlyGen concept. } \\
\text { Generator on board. The } \\
\text { tether carries energy } \\
\text { from the kite to the grid, } \\
\text { connecting it to the } \\
\text { ground station. }\end{array}$ & $\begin{array}{l}30 \mathrm{~kW} \text { prototype. } \\
\text { Recently shifted from } \\
\text { flexible to rigid airfoils. }\end{array}$ & $\begin{array}{l}\text { - Conducting tethering cables instead } \\
\text { of insulating ropes as in KiteGen. } \\
\text { - Harnessing propellers which add } \\
\text { drag thus limiting the aerodynamic } \\
\text { efficiency of the system. } \\
\text { - Risk of total investment loss should } \\
\text { a crash occur }\end{array}$ & \\
\hline $\begin{array}{l}\text { KiteGen } \\
\text { Research } \\
\text { Italy }\end{array}$ & $\begin{array}{l}\text { Two tether Groundgen } \\
\text { concept with composite } \\
\text { sensorized Power Wing. } \\
\text { Mechanical energy } \\
\text { brought to ground alter- } \\
\text { nators using ropes. }\end{array}$ & $\begin{array}{l}100 \mathrm{~kW} \text { prototype first } \\
\text { produced energy in } \\
\text { 2006. Composite Wing } \\
\text { designed and realized. } \\
\text { 3MW double stem } \\
\text { generator industrializa- } \\
\text { tion ongoing }\end{array}$ & $\begin{array}{l}\text { - Rope doubled to solve safety and } \\
\text { piloting issues adds more drag. } \\
\text { - Big wing needs careful handling }\end{array}$ & \\
\hline $\begin{array}{l}\text { Altaeros } \\
\text { USA }\end{array}$ & $\begin{array}{l}\text { Tethered airborne } \\
\text { platforms designed to } \\
\text { lift a lightweight wind } \\
\text { turbine up to } 600 \mathrm{~m} \\
\text { above ground. }\end{array}$ & $\begin{array}{l}\text { First functional BAT } \\
\text { prototype launched } \\
\text { in 2012. The company } \\
\text { is claiming to work on } \\
\text { the first commercial } \\
\text { scale BAT. }\end{array}$ & $\begin{array}{l}\text { - Need of helium (non renewable } \\
\text { source). } \\
\text { - The trigonometric ratio between } \\
\text { buoyancy force and wind drag } \\
\text { vectors excludes them from the } \\
\text { category of tropospheric wind. }\end{array}$ & \\
\hline $\begin{array}{l}\text { X-Wind } \\
\text { Germany }\end{array}$ & $\begin{array}{l}\text { Combines automatically } \\
\text { steered kites, grounded } \\
\text { rail systems and cable } \\
\text { car technology on linear } \\
\text { or circular track. }\end{array}$ & $\begin{array}{l}\text { A 400m linear test } \\
\text { track is in operation } \\
\text { since } 2011 \text {. Closed } \\
\text { loop prototype is un- } \\
\text { der construction. }\end{array}$ & $\begin{array}{l}\text { - No relevant patent coverage, they } \\
\text { patented a blimps rail generator. } \\
\text { - Rail concept presumably devel- } \\
\text { oped in infringement with KiteGen } \\
\text { Carousel patent. }\end{array}$ & \\
\hline $\begin{array}{l}\text { Sky Wind } \\
\text { Power } \\
\text { Germany }\end{array}$ & $\begin{array}{l}\text { Flying electric generator } \\
\text { with rotors that both lift } \\
\text { the vehicle and convert } \\
\text { the kinetic energy } \\
\text { into electricity. }\end{array}$ & $\begin{array}{l}\text { Small prototype tested } \\
\text { in December } 2011 \\
\text { flying with additional } \\
\text { safety tethers through } \\
\text { a limited range of the } \\
\text { required maneuvers. }\end{array}$ & $\begin{array}{l}\text { - Conducting tethering cables } \\
\text { - Heavy structure suitable for jet } \\
\text { streams exploitation only. }\end{array}$ & \\
\hline $\begin{array}{l}\text { Amphyx } \\
\text { Power } \\
\text { Netherlands }\end{array}$ & $\begin{array}{l}\text { PowerPlanes flying } \\
\text { repetitive cross-wind } \\
\text { patterns, attached with } \\
\text { a cable to a ground- } \\
\text { based generator. }\end{array}$ & $\begin{array}{l}10 \mathrm{~kW} \text { scale prototype } \\
\text { with rigid airfoils. }\end{array}$ & $\begin{array}{l}\text { - No patent coverage } \\
\text { - Lack of scalability due to the flat } \\
\text { wing that require a heavy longeron } \\
\text { to sustain the wind force. }\end{array}$ & \\
\hline $\begin{array}{l}\text { Sky Sails } \\
\text { Germany }\end{array}$ & $\begin{array}{l}\text { Ship traction using } \\
\text { crosswind power. } \\
\text { Traction power-kite with } \\
\text { flying actuators. }\end{array}$ & $\begin{array}{l}50 \mathrm{~kW} \text { prototype already } \\
\text { sold to pilot customers. }\end{array}$ & $\begin{array}{l}\text { Patent coverage for ship traction but } \\
\text { not for energy production. }\end{array}$ & \\
\hline
\end{tabular}

of the wind power window spot in combination with the flying path that is called "exo-phanic lemniscate". It is obvious that this behaviour could only appear with a model that computes and describes a full flying cycle including the wing attitudes and the rope discretizing, a simplified snap of an instant is meaningless.

Still there are important features missing in current analysis, as for instance the coupling between rope and kite without rotational constraints discussed in the previous Section. However, it seems that slowly a realistic model of pumping kite power generation is being settled, and most of interested scientists and active players do believe there is room for optimization of energy extraction from wind in the sky region up to at least $3000 \mathrm{~m}$ a.g.l. (see, for instance, [26] and [27]) $\triangle$ TABLE 1: State of the art of HAWES technology developed by some representative companies. 


\section{State of the art and last developments}

We want to underline once again that the different technologies of HAWES are still in their infancy and significative developments towards industrialization have been performed only in the second decade of the century. Nevertheless, as said above, many players were able to give experimental demonstrations of their feasibility. Table 1 shows the state of the art of technical developments achieved by some representative, even though not exhaustive, industrial players.

Ongoing developments include the search for a fully automated flight control, performed by many public research organizations and private companies; sensors and radio communication device fit-out to assure a maximum safety level; an educational and communication strategy to increase the working expertise in this sector and public awareness of the paramount importance of this energy resource.

Despite the short development time, many important results have been achieved until now, so that the scientific community must consider high wind exploitation more than a promise, rather a real opportunity. However, apart from some exceptions represented by a small number of universities and the US organization NASA, public involvement, funding, and acknowledgement of HAWE technologies have been very shy or even absent. This fact appears in evident contradiction with global energetic, economic, and environmental needs, and with public declarations of most of governmental bodies around the world.

\section{About the Authors}

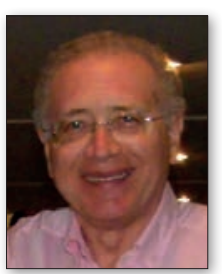

Giancarlo Abbate (abbate@unina.it) is a full Professor of Physics at Università di Napoli Federico II. He started his scientific activity in the 70s in the field of optics and nonlinear optics of liquid crystals and soft materials and has authored a number of scientific papers, and chaired a large European project on this subject. He is member of several scientific societies, and was member of the advisory board (20) and chair (10) of International Conferences. He also got one patent. In the last decade, his main interest has been in the field of energy, and in particular renewable energy. He was in the scientific committee of KiteGen Research. He has been external advisor for private companies and public research organizations. In 2017, he founded a spin-off company of the University of Naples Federico II, with the aim of developing and producing supercapacitors for energy storage applications.

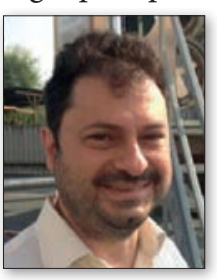

Eugenio Saraceno (eugeniosaraceno@ gmail.com) is a computer engineer and master in energy management. He started working as a software engineer in the field of telecommunications. He has been a consultant for the main Italian telecommunication companies and for the Central Bank of Italy. He is currently working for the KiteGen Project as a Software Architect.

\section{References}

[1] Gustavson, Science 204, 4388 (1979)

[2] R. Perez and M. Perez, IEA-SHCP-Newsletter Vol. 62, Nov. $2015^{* *}$ High Wind Included by Massimo Ippolito KiteGen Research.

[3] www.wind-power-program.com/mean_power_calculation.htm

[4] www.researchgate.net/publication/262920791_Observations of_wind_speed_profiles_over_Greater_London_UK_using a_Doppler_lidar

[5] C. L. Archer, K. Caldeira, Atlas of high altitude wind power, Department of Global Ecology, Carnegie Institute for Science, 260 Panama Street, Stanford, CA 94305, 16 June 2008.

[6] Chak Man Andrew Yip, Udaya Bhaskar Gunturu \& Georgiy L. Stenchikov-High-altitude wind resources in the Middle East Scientific Reports 7, Article number: 9885 (2017)

[7] G. Pocock, The Aeropleustic Art or Navigation in the Air by the use of Kites, or Buoyant Sails - London: 1827

[8] M. L. Loyd, Crosswind kite power, Journal of Energy 4(3), 106 (1980)

[9] www.youtube.com/watch?v=raWyvOsORZM

[10] www.youtube.com/watch?v=SVi_-dIDVcw

[11] www.ted.com/talks/saul_griffith_on_kites_as_the future_of_renewable_energy

[12] www.youtube.com/watch?v=demmPybYf2I

[13] windlift.com/video.html

[14] www.youtube.com/watch?v=DgRTCH-J48c

[15] www.youtube.com/watch?v=DCfw1B2XGQc

[16] www.youtube.com/watch?v=MlvfbpwSYKs

[17] http://twingtec.ch/twingtec-in-the-einstein-swiss-tv-show/

18] A. Cherubini et al., Renewable and Sustainable Energy Reviews 51, 1461 (2015).

[19] www.kitegen.com

[20] CESI RICERCA (now RSE) - Valutazione sui sistemi " kite wind generator" (2009) www.kitegen.com/docs/ P 212012 CESI RICERCA Valutazioni sui sistemi Kite Wind Generator - 2009.pdf

[21] I.Argatov, P. Rautakorpi, R. Silvennoinen, Journal of Wind Engineering and Industrial Aerodynamics 99(10), 1079 (2011) https://doi.org/10.1016/j.jweia.2011.07.010

[22] I.Argatov, P. Rautakorpi, R. Silvennoinen, Renewable Energy 34, 1525 (2009)

[23] I.Argatov, R. Silvennoinen, Renewable Energy 35, 1052 (2010)

[24] L. Fagiano, 2009. Control of Tethered Airfoils for High-Altitude Wind Energy Generation. P.hD. Thesis, Politecnico di Torino http://lorenzofagiano.altervista.org/docs/PhD_thesis_ Fagiano_Final.pdf

[25] F. Roselli, Study on the dynamics of the flexible cables of a KITE-GEN type of energy generator Thesis, Politecnico di Torino Dipartimento di Energetica (Mar.2016)

[26] L. Goldstein, Energy 55, 987 (2013)

[27] C. L. Archer et al., Renewable Energy 64, 180 (2014) 